\title{
Alcohol and drug use by Spanish drivers: Comparison of two cross-sectional road-side surveys (2008-9/2013)
}

\author{
Inmaculada Fierro $^{\text {a,* }}$, Juan Carlos González-Luque ${ }^{\text {, }}$, María Seguí-Gómez ${ }^{\text {, }}$, \\ F. Javier Álvarez ${ }^{a}$ \\ ${ }^{a}$ Institute for Alcohol and Drug Studies, Faculty of Medicine, 47005 Valladolid, Spain \\ ${ }^{\mathrm{b}}$ Directorate General for Traffic, 28071 Madrid, Spain
}

\section{Introduction}

Driving under the influence of substances (DUI) other than alcohol has been the subject of increasing interest over the past few decades (Schulze et al., 2012). As with alcohol, research has shown that drug intake increases the risk of road traffic accidents (Elvik, 2013; Schulze et al., 2012; Verstraete \& Legrand, 2014). Intervention in this area is a priority. A key factor for deterring DUI is to convince drug-using drivers that the risk of detection is high (Jones, Donnelly, Swift, \& Weatherburn, 2006; Watling, Palk, Freeman, \& Davey, 2010) thus, adequate law enforcement, and the continuity of roadside testing for drug use among drivers, play an important role (Shepherd, 2001; Watson \& Freeman, 2007).

For the European Project DRUID (Driving under the Influence of Drugs, Alcohol and Medicines; http://www.druid-project.eu), roadside surveys were conducted in 13 European countries and results showed large differences in the prevalence of alcohol and drug intake by country (Schulze et al., 2012). The highest prevalence was found in Southern Europe (Italy, Spain and Portugal). In Spain, avoiding driving after alcohol or drug use has been recognized as crucial to improving road safety. Five years after the DRUID project, a new roadside survey was conducted following a similar methodology in order to study whether the use of alcohol and drugs among Spanish drivers had changed.

\section{Methods}

The survey target population was motor vehicle drivers, excluding bikers and drivers of vehicles over $3500 \mathrm{~kg}$, on Spanish public roads. The prevalence of drivers under the influence of substances was compared using results of two cross-sectional studies conducted in 2008-9 (time 1) and 2013 (time 2) in separate representative samples of the general population of Spanish drivers. Drivers were selected at random from the total population

\footnotetext{
* Corresponding author. Tel.: +34 983423077; fax: +34 983423077.

E-mail address: inma@lti.uva.es (I. Fierro).
}

of drivers using a sampling scheme stratified by country areas, time period, population size, and road type, following DRUID criteria as previously described (Gómez-Talegón et al., 2012). A total of 128 police roadside checkpoints were selected. The data were weighted according to the traffic intensity at each checkpoint. The study included a total sample size of 6234 drivers: 3302 at time 1 (with samples taken between September 26th, 2008 and August 24th, 2009) and 2932 at time 2 (with samples taken at two different time periods, May and November). In Spain, roadside police controls are legally regulated. Alcohol test and onroad saliva analysis are both mandatory. Refusal to be tested has the same penalty as a positive test (1000 euros fine and a loss of 6 driver points). Therefore, no drivers refused to participate. However, in 20 cases in 2008-9, the driver was either unable to produce enough saliva to carry out the drug test or there was an error with the device being used. In 2013, five drivers were unable to produce enough saliva to test.

\section{Substances analyzed and toxicological aspects}

Roadside police controls used mandatory alcohol tests and onroad saliva analysis. Breath tests for alcohol were carried out using the Dräger Alcotest ${ }^{\circledR} 6810$ device and an on-site oral fluid drugs test (screening), with the Dräger Drug Test ${ }^{\circledR} 5000$ analyzer (Dräger, 2015). Identical (having the same technical specifications and cut offs) (Gómez-Talegón et al., 2012) test kits were used at time 1 and 2 for multiple and simultaneous detection of amphetamines, methamphetamines, opiates, cocaine, cannabis and benzodiazepines. The oral fluid samples used in the confirmatory analysis were collected with the StatSure ${ }^{\mathrm{TM}}$ Saliva•Sampler ${ }^{\mathrm{TM}}$ for the first group of samples (time 1) and with Quantisal $^{\mathrm{TM}}$ in the second (time 2). The Statsure and Quantisal devices contained 1.0 and $3 \mathrm{ml}$ of buffer respectively. The collected volumes of oral fluid were determined for each sample by weight. Drug concentrations in undiluted oral fluid were calculated by considering oral fluid density as $1 \mathrm{~g} / \mathrm{ml}$ (Concheiro, de Castro, Quintela, Cruz, \& López-Rivadulla, 2008). The analyses were carried out at both times by the University of Santiago de Compostela. The storage and cooling process, transportation and 
Table 1

Analyzed substances and cut-off concentrations in native oral fluid determining positivity according to DRUID criteria (Gómez-Talegón et al., 2012).

\begin{tabular}{lcc}
\hline Substance & $\begin{array}{c}\text { Oral fluid analytical } \\
\text { cut-off }(\mathrm{ng} / \mathrm{ml})\end{array}$ & Breath $(\mathrm{mg} / \mathrm{L})$ \\
\hline Ethanol & \multicolumn{1}{c}{0.05} \\
6-Acetilmorphine & 16.0 & \\
Alprazolam & 3.5 & \\
Amphetamine & 360.0 & \\
Benzoilecgonine & 95.0 & \\
Clonazepam & 1.7 & \\
Cocaine & 170.0 & \\
Codeine & 94.0 & \\
Diazepam & 5.0 & \\
Flunitrazepam & 1.0 & \\
Lorazepam & 1.1 & \\
MDA & 220.0 \\
MDEA & 270.0 \\
MDMA & 270.0 \\
Metadone & 22.0 \\
Metamphetamine & 410.0 & \\
Morphine & 95.0 & \\
Nordiazepam & 1.1 & \\
Oxazepam & 13.0 & \\
THC & 27.0 & \\
Zolpidem & 10.0 & \\
Zopiclone & 25.0 & \\
Tramadol & 480.0 & \\
7-Amino-clonazepam & 3.1 & \\
\hline
\end{tabular}

subsequent analysis in the laboratory has previously been described (Gómez-Talegón et al., 2012). At time 2, only the samples of drivers testing positive in the screening were later analyzed in the laboratory. Consequently, the variables at time 1 were recodified following the same criteria. Samples were categorized as "negative" when the drivers' results were negative in the screening test. For both studies, a final positive result was defined as a concentration higher than the cut-offs established in the DRUID project for any of the analyzed substances in the laboratory, or having a breath alcohol concentration of $>0.05 \mathrm{mg} / \mathrm{L}$ (Table 1).

The positives in the screening were defined in terms of four dichotomous variables (yes/no): "only alcohol", "only drugs", "alcohol and drugs" and "any substance". Regarding confirmatory analysis, two variables were considered: "any substance" (yes/no) and a categorical variable with nine groups: negative/THC positive/ cocaine positive/amphetamine positive/opiate positive/alcohol positive/benzodiazepine positive/positive for a combination of drugs/alcohol + drug positive.

\section{Statistical analyses}

Absolute and relative frequencies with 95\% confidence intervals (CIs) are shown. The two-tailed two-proportion $z$-test was used to determine whether the difference between two proportions was significant. Statistical analyses were carried out with the Statistical Package for the Social Sciences (SPSS, v19). The level of significance was set at $p \leq 0.05$.

\section{Results}

At time $2,12.07 \%$ of the on-road traffic controls tested positive for alcohol and/or drugs in the screening test, which shows a decrease of 4.27 points compared with time 1 (16.34\% Table 2$)$. At time 2, cases testing positive for both alcohol and drugs were also less frequently observed. Compared to time 1 , there was a decrease in the prevalence of cases testing positive for alcohol (and negative for drugs) as well as cases testing positive for drugs (and negative for alcohol).

At time 2, 9.34\% of cases were confirmed to have some substance present compared to $14.05 \%$ at time 1 , indicating a decrease of 4.71 points (Table 2). A decrease was observed in the prevalence of cases testing positive for alcohol and drugs from 2008-9 to 2013. Upon analyzing the different combinations of substances, differences were observed in the cases testing positive only for alcohol, alcohol and drugs (Table 2), and for drugs without the presence of alcohol or medicines (time 1: 6.93\% [6.07-7.80]; time 2: 4.87\% [4.09-5.65]; $p<0.01)$. The decrease in the prevalence of drugs was due to the less frequent presence of cannabis, while prevalence of the other categories of illegal drugs showed no change (Table 2).

\section{Discussion}

The results show that the presence of alcohol, drugs, and medicines continues to be frequent among tested Spanish drivers. However, data from 2013 clearly show a decrease in the prevalence of cases that tested positive for alcohol and/or drugs on the roadside screening test (a decrease of 4.27 points, or a decrease of $26.13 \%$ with respect to $2008-9$ ) as well as in the laboratory test

Table 2

Results of the screening tests, confirmation of the presence of drugs in oral fluid, and breath alcohol concentration (roadside surveys 2008-9 and 2013).

\begin{tabular}{|c|c|c|c|c|c|}
\hline & \multicolumn{2}{|c|}{ Roadside survey 2008-9 $(n=3302)$} & \multicolumn{2}{|c|}{ Roadside survey $2013(n=2932)$} & \multirow[t]{2}{*}{ Test $z ; p$} \\
\hline & $n$ & $\%[95 \% \mathrm{CI}]$ & $n$ & $\%[95 \% \mathrm{CI}]$ & \\
\hline \multicolumn{6}{|l|}{ Screening } \\
\hline Negative & 2763 & $83.66[82.40-84.92]$ & 2578 & $87.90[86.72-89.08]$ & $4.744 ; p<0.0001$ \\
\hline Total positive for alcohol or drug screening & 539 & $16.34[15.08-17.60]$ & 354 & $12.07[10.92-13.28]$ & $4.744 ; p<0.0001$ \\
\hline +alcohol/-drug screening & 151 & $4.58[3.86-5.29]$ & 97 & $3.30[2.66-3.95]$ & $2.485 ; p<0.05$ \\
\hline -alcohol/+drug screening & 321 & $9.73[8.72-10.74]$ & 233 & $7.96[6.98-8.94]$ & $2.413 ; p<0.05$ \\
\hline +alcohol/+drug screening & 67 & $2.03[1.55-2.51]$ & 24 & $0.81[0.48-1.13]$ & $3.872 ; p<0.0001$ \\
\hline \multicolumn{6}{|l|}{ Results of confirmatory analyses } \\
\hline No substance & 2838 & $85.95[84.71-87.09]$ & 2658 & $90.65[89.66-91.76]$ & $5.702 ; p<0.0001$ \\
\hline Substance & 464 & 14.05 [12.91-15.29] & 274 & $9.34[8.24-10.34]$ & $5.702 ; p<0.0001$ \\
\hline Cannabis (THC) & 174 & $5.28[4.51-6.04]$ & 92 & $3.13[2.50-3.76]$ & $4.094 ; p<0.0001$ \\
\hline Cocaine & 42 & 1.28 [0.90-1.67] & 26 & $0.87[0.54-1.21]$ & $1.339 ; p>0.05$ \\
\hline Amphetamines & 2 & $0.06[0.00-0.15]$ & 4 & $0.12[0.00-0.25]$ & $0.555 ; p>0.05$ \\
\hline Opiates & 5 & $0.14[0.01-0.27]$ & 1 & 0.03 [0.00-0.09] & $1.082 ; p>0.05$ \\
\hline Alcohol $>0.05$ & 162 & $4.92[4.18-5.66]$ & 100 & $3.41[2.27-4.07]$ & $2.874 ; p<0.05$ \\
\hline Benzodiazepines & 5 & $0.17[0.03-0.30]$ & 3 & $0.09[0.00-0.20]$ & $0.186 ; p>0.05$ \\
\hline Multiple drugs & 18 & $0.55[0.30-0.81]$ & 26 & $0.90[0.55-1.24]$ & $1.457 ; p>0.05$ \\
\hline Alcohol+drugs & 56 & $1.69[1.25-2.13]$ & 22 & $0.72[0.42-1.04]$ & $3.238 ; p<0.05$ \\
\hline
\end{tabular}


confirmation (a decrease of 4.71 points, or a decrease of $33.52 \%$ with respect to 2008-9). Even with these favourable results, the prevalence of cases of drivers under the influence of alcohol and drugs is high, and highlights the need for continued intervention in this area.

From a practical point of view, the results of the screening tests are decisive when it comes to police procedure. In some countries, including Spain, when there is a case in which the alcohol screening has tested positive, there is usually no further drug testing. One can observe that in the 2008-9 and 2013 studies, the cases testing positive for alcohol are those that show a breath alcohol concentration of $0.05 \mathrm{mg} / \mathrm{L}$ or more. Nevertheless, the legal limit in Spain is $0.25 \mathrm{mg} / \mathrm{L}(0.15 \mathrm{mg} / \mathrm{L}$ in novel drivers). The 2013 data show a reduction in cases testing positive for alcohol, and in cases positive for alcohol and drugs.

The medicinal drugs analyzed were benzodiazepines, some hypnotic drugs, and some opioids. As a consequence, the information obtained in this study is limited to those specific pharmaceutical groups and only represents part of the problem of drivers under the influence of medicines. Benzodiazepines can be used in the treatment of mental disorders or can be used illicitly without a prescription. From a road safety perspective, these are two different problems. The presence of pharmaceuticals was detected in 24 drivers in 2008-9 and in eight drivers in 2013. Spain has introduced a pictogram for medicinal drugs, which informs the driver about a possible reduction in ability to drive safely when using those medicines (Fierro, Gómez-Talegón, \& Alvarez, 2013). This pictogram is printed on the packaging of benzodiazepines, hypnotic drugs and opioids. In the context of the European DRUID project, medicines were categorized into four groups (Ravera et al., 2012). While illicit drugs are non-regulated substances, medicines are prescribed by physicians and dispensed by pharmacists with the possibility of receiving appropriate information regarding ability to drive. Finding a case testing positive to medication can raise issues for both the police and for government bodies. As a current policy, the Spanish government has decided not to include benzodiazepines in road drug testing.

This study has a number of limitations. Firstly, while the same design and selection criteria were used for both surveys, at time 1 the testing was carried out over an 11 month period, and at time 2, at two points in time, in May and November. National bank holidays were taken into account at time 1 but not at time 2 . The rationale for this was that analysis at time 1 revealed that bank holidays and month of year had no effect $(p>0.05)$ on the prevalence of positive cases. However, the different design at time 1 and 2 may have had an impact on the figures observed. Secondly, at both times the same testing criteria, cut-offs and confirmation processes were used. Saliva was collected with StatSure ${ }^{\mathrm{TM}}$ in time 1 and Quantisal ${ }^{\mathrm{TM}}$ in time 2 as the StatSure ${ }^{\mathrm{TM}}$ device had disappeared from the market by time 2 and the Quantisal ${ }^{\mathrm{TM}}$ device the best substitute. Although a lower recovery for the THC from the Quantisal ${ }^{\mathrm{TM}}$ device than from the StatSure ${ }^{\mathrm{TM}}$ device was observed (Langel et al., 2008), other studies have also found good recovery for THC from the Quantisal ${ }^{\mathrm{TM}}$ device (Quintela et al., 2006; Moore et al., 2006). In our case, all oral fluid samples (for time 1 and 2) were analyzed in the same forensic toxicology service laboratory at the University of Santiago de Compostela and they found the highest recovery for THC from the Quantisal ${ }^{\mathrm{TM}}$ device (Quintela et al., 2006). A decrease in the prevalence of drugs was observed, even when taking into account that the amount of drug recovered from the Quantisal ${ }^{\mathrm{TM}}$ device was probably higher than the StatSure ${ }^{\mathrm{TM}}$, especially for the THC. Thirdly, changes observed between time 1 and 2 could be related to changes in the prevalence of drug use among the population. Data from the Spanish national drug use surveys on the adult population (15-65 years old) are collated every two years, and there are data from 1995 to 2013
(PNSD, 2015). Figures on cannabis, do not show a clear trend between 2007 and 2013: lifetime use, 2007, 27.3\%; 2009, 32.1\%; $2011,27.4 \%$; 2013, 30.4\%; past-month use 2007, 7.2\%; 2009, 7.6\%, $2011,7.0 \%$; 2013, 6.6\%; daily use in the past month $2007,1.7 \%$, $2009,2.0 \%, 2011,1.7 \%$; 2013, 1.9\%. Regarding cocaine and stimulant drugs, there may be a decreasing trend in use over these years.

Although this study's design does not allow us to determine all the factors behind this decrease, the routine implementation of roadside drug tests may have been a contributing factor. As previously noted (DRUID, 2009, p. 11), "the experience of random testing in traffic in Victoria (Australia) showed that on-site screening devices have a good performance as a deterrent, leading to a marked decrease in the prevalence of THC, MDMA and methamphetamine, the three drugs which are covered in the states legislation". However, the deterrence effect depends on the frequency of testing as well as the context and may vary significantly with time (Watson \& Freeman, 2007). Because of this, the deterrence effects of random drug testing and the legislative framework must be evaluated as well as their usefulness in promoting road safety.

Cannabis dependence and frequency of use have shown significant associations with DUI of cannabis (Jones et al., 2006). A key factor for deterring DUI is to convince drug-using drivers that their risk of detection is high (Jones et al., 2006). However, the severity of punishment does not produce a reduction in DUI of cannabis. A recent study in Victoria (Australia) suggested that interventions which address the risk associated with DUI may be beneficial, particularly those that emphasise the risk of motor vehicle crashes. Moreover, in this study, cannabis was noted as special case of intervention due to cannabis users' reluctance to change (Matthews, Bruno, Dietze, Butler, \& Burns, 2014).

In 2010, legislative measures were introduced which established the validity of oral fluid (saliva) as biological evidence for testing and made the testing mandatory along with the consequent confirmatory analysis if the screening test were to be positive (Ley Orgánica 5/2010). In 2014, a new regulation (Ley 6/2014) has been introduced which, among other things, increased the fine to 1000 Euro (and a loss of 6 penalty points) for driving under the influence of drugs.

In conclusion, this study shows a decrease in the prevalence of cases testing positive for substances among Spanish drivers. Despite the marked decrease, detection of alcohol, drugs, and medicines among Spanish drivers remain common. Preventing driving under the influence of substances is a priority for road safety, particularly in Spain where new legislation (2014) was introduced to increase the fines for driving under the influence. The political priority given to drug driving in recent years has resulted in the extension of on-road drug testing. The data from the DRUID project shows that an extremely increased risk (relative risk 20200) was observed among drivers with alcohol in blood $\geq 1.2 \mathrm{~g} / \mathrm{l}$ and among those with alcohol in combination with drugs; we have observed a sensible decrease in alcohol + drugs between 2008-9 (1.69\%) and 2013 (0.72\%). The implementation of these measures in Spain has helped make driving under the influence of drugs less frequent.

\section{Conflict of interest}

The authors confirm that there are no conflicts of interests.

\section{Acknowledgements}

This study has been possible thanks to the collaboration of Spanish traffic police. We also wish to express our thanks to 
the staff of the laboratory of the Forensic Toxicology Service, of the University of Santiago de Compostela, who carried out the toxicological analysis by LC-MS/MS quantification. Funding for this study was provided by grants from the EU 6th Framework Programme, DRUID project (Project No. REN-05-FP6TR-S07.61320518404-DRUID), Directorate General for Traffic (DGT, Dirección General de Tráfico) (Project No. Exp.: 0100DGT23059) and the Instituto de Salud Carlos III, Redes Temáticas de Investigación Cooperativa, Red de Trastornos Adictivos Project No. RD12/0028/ 00212.

\section{References}

Concheiro, M., de Castro, A., Quintela, O., Cruz, M., \& López-Rivadulla, M. (2008) Determination of illicit and medical drugs and their metabolites in oral fluid and preserved oral fluid by liquid chromatography-tandem mass spectrometry. Analytical and Bioanalytical Chemistry, 391, 2329-2338.

Dräger (2015). Dräger DrugTest ® 5000. Retrieved from http://www.draeger.com/sites/ en_aunz/Pages/Alcohol-and-Drug-Detection/Draeger-DrugTest-5000.aspx

DRUID (Driving Under the Influence of Drugs, Alcohol and Medicines) (2009). Protocol of "Workshop on drug driving detection by means of oral fluid screening", deliverable D 3.2.1. Retrieved from http://www.druid-project.eu/Druid/EN/deliverales-list/ downloads/Deliverable_3_2_1.pdf?_blob=publicationFile

Elvik, R. (2013). Risk of road accident associated with the use of drugs: A systematic review and meta-analysis of evidence from epidemiological studies. Accident Analysis \&' Prevention, 60, 254-267.

Fierro, I., Gómez-Talegón, T., \& Alvarez, F. J. (2013). The Spanish pictogram on medicines and driving: The population's comprehension of and attitudes towards its use on medication packaging. Accident Analysis E Prevention, 50, 1056-1061.

Gómez-Talegón, T., Fierro, I., González-Luque, J. C., Colás, M., López-Rivadulla, M., \& Álvarez, F. J. (2012). Prevalence of psychoactive substances, alcohol, illicit drugs, and medicines, in Spanish drivers: A roadside study. Forensic Science International, 223, 106-113.

Jones, C., Donnelly, N., Swift, W., \& Weatherburn, D. (2006). Preventing cannabis users from driving under the influence of cannabis. Accident Analysis E Prevention, 38, 854-861.
Langel, K., Engblom, C., Pehrsson, A., Gunnar, T., Ariniemi, K., \& Lillsunde, P. (2008). Drug testing in oral fluid-evaluation of sample collection devices. Journal of Analytical Toxicology, 32, 393-401.

Ley 6/2014 de 7 de abril. BOE número 85 de 8/4/2014. Sec. 1, pp. 29508-29524. Retrieved from http://www.boe.es/boe/dias/2014/04/08/pdfs/BOE-A-2014-3715. pdf

Ley Orgánica 5/2010 de 22 de junio por la que se modifica la Ley Orgánica 10/1995, de 23 de noviembre, del Código Penal. Retrieved from http://www.boe.es/boe/dias/ 2010/06/23/pdfs/BOE-A-2010-9953.pdf

Matthews, A. J., Bruno, R., Dietze, P., Butler, K., \& Burns, L. (2014). Driving under the influence among frequent ecstasy consumers in Australia: Trends over time and the role of risk perceptions. Drug and Alcohol Dependence, 144, 218-224.

Moore, C., Vincent, M., Rana, S., Coulter, C., Agrawal, A., \& Soares, J. (2006). Stability of Delta(9)-tetrahydrocannabinol (THC) in oral fluid using the Quantisal collection device. Forensic Science International, 164, 126-130.

Plan Nacional Sobre Drogas (PNSD) (2015). Encuestas y Estudios. EDADES 2013. Retrieved from http://www.pnsd.msc.es/Categoria2/observa/estudios/home.htm

Quintela, O., Crouch, D. J., \& Andrenyak, D. M. (2006). Recovery of drugs of abuse from the Immunalysis Quantisal oral fluid collection device. Journal of Analytical Toxicology, 30, 614-616.

Ravera, S., Monteiro, S. P., de Gier, J. J., van der Linden, T., Gómez-Talegón, T., \& Alvarez, F. J. (2012). DRUID Project WP4 Partners. A European approach to categorizing medicines for fitness to drive: Outcomes of the DRUID project. British Journal of Clinical Pharmacology, 74, 920-931.

Shepherd, J. P. (2001). Criminal deterrence as a public health strategy. Lancet, 358, 1717-1722.

Schulze, H., Schumacher, M., Urmeew, R., Auerbach, K., Alvarez, F. J., Bernhoft, I. M., et al. (2012). Driving Under the Influence of Drugs, Alcohol and Medicines in EuropeFindings from the DRUID project. European Monitoring Centre for Drugs and Drug Addiction. EMCDDA in Lisbon. Retrieved from http://www.emcdda.europa.eu/ attachements.cfm/att_192773_EN_TDXA12006ENN.pdf

Verstraete, A. G., \& Legrand, S. A. (2014). Drug use, impaired driving and traffic accidents. European Monitoring Centre for Drugs and Drug Addiction. EMCDDA in Lisbon. Retrieved from http://www.emcdda.europa.eu/attachements.cfm/ att_229259_EN_TDXD14016ENN.pdf

Watling, C. N., Palk, G. R., Freeman, J. E., \& Davey, J. D. (2010). Applying Stafford and Warr's reconceptualization of deterrence theory to drug driving: Can it predict those likely to offend? Accident Analysis \& Prevention, 42, 452-458.

Watson, B., \& Freeman, J. (2007). Perceptions and experiences of random breath testing in Queensland and the self-reported deterrent impact on drunk driving. Traffic Injury Prevention, 8, 11-19. 